\title{
Bacteremia caused by Enterobacter asburiae misidentified biochemically as Cronobacter sakazakii and accurately identified by matrix-assisted laser desorption/ionization time-of-flight mass spectrometry: a case report
}

Noboru Horinouchi ${ }^{1,2}$, Seiji Shiota ${ }^{1,2^{*}} \mathbb{0}$, Takeshi Takakura ${ }^{1}$, Atsushi Yoshida ${ }^{3}$, Ken Kikuchi ${ }^{3}$, Akira Nishizono $^{4}$ and Eishi Miyazaki ${ }^{2}$

\begin{abstract}
Background: Biochemical analyses of causative bacteria do not always result in clear identification, and new technologies aimed at improving diagnostic accuracy continue to be developed. Matrix-assisted laser desorption/ionization time-of-flight mass spectrometry is a rapid and accurate technique for bacterial identification. Misidentification of Cronobacter sakazakii is related to clinical and industrial problems. Here, we encountered a case of rare bacteremia in which the causative organism Enterobacter asburiae was biochemically misidentified as C. sakazakii before being correctly identified by matrix-assisted laser desorption/ionization time-of-flight mass spectrometry.
\end{abstract}

Case presentation: An 87-year-old Asian man with no diabetes or active disease developed bacteremia and was admitted to our hospital. While the route of infection could not be determined despite various examinations, the clinical course was good following antibiotic therapy. Biochemical analyses identified the causative organism as C. sakazakii, but colonies on the blood agar medium showed a grayish coloration, differing from the yellowish coloration of typical Cronobacter colonies. Matrix-assisted laser desorption/ionization time-of-flight mass spectrometry was therefore performed, identifying the bacterium as E. asburiae on three independent analyses. This result was confirmed by multilocus sequence analysis using five housekeeping genes.

Conclusions: Matrix-assisted laser desorption/ionization time-of-flight mass spectrometry may reduce misidentification of bacteria as C. sakazakii and improve the reporting rate of E. asburiae. This technique should be considered when biochemical bacterial misidentification is suspected.

Keywords: Enterobacter asburiae, Cronobacter sakazakii, Matrix-assisted laser desorption/ionization time-of-flight mass spectrometry

*Correspondence: sshiota@oita-u.ac.jp

1 Department of General Medicine, Almeida Memorial Hospital, 1509-2 Miyazaki, Oita, Oita 870-1195, Japan

Full list of author information is available at the end of the article

\section{Background}

Identification of the causative bacteria for infectious diseases using biochemical examinations is sometimes inaccurate, and new technologies aimed at improving diagnostic accuracy continue to be developed. Matrixassisted laser desorption/ionization time-of-flight mass original author(s) and the source, provide a link to the Creative Commons licence, and indicate if changes were made. The images or other third party material in this article are included in the article's Creative Commons licence, unless indicated otherwise in a credit line to the material. If material is not included in the article's Creative Commons licence and your intended use is not permitted by statutory regulation or exceeds the permitted use, you will need to obtain permission directly from the copyright holder. To view a copy of this licence, visit http://creativecommons.org/licenses/by/4.0/. The Creative Commons Public Domain Dedication waiver (http://creativeco mmons.org/publicdomain/zero/1.0/) applies to the data made available in this article, unless otherwise stated in a credit line to the data. 
spectrometry (MALDI-TOF MS) allows rapid, accurate identification of the causative organism. This technique analyzes the patterns of proteins that are extracted from bacteria, which can reveal bacteria at the genus, species, and sometimes even subspecies levels [1].

Both Cronobacter sakazakii and Enterobacter asburiae are Gram-negative, rod-shaped, motile bacteria. C. saka$z a k i i$ is an opportunistic pathogen that can cause lethal infection in newborns and the elderly, so accurate identification is crucial and misidentification by biochemical examination represents a critical problem [2]. C. sakazakii was initially identified under the genus Enterobacter before being recategorized under the genus Cronobacter [3]. Distinguishing between Cronobacter and Enterobacter is difficult due to the similarities in biochemical phenotypes [2]. Rapid, reliable identification of genus Cronobacter and differentiation from genus Enterobacter is important for epidemiological research. Here, we report a case of bacteremia in which the causative E. asburiae was initially misidentified as $C$. sakazakii by biochemical analyses before eventual correct identification by MALDI-TOF MS.

\section{Case presentation}

An 87-year-old Asian man visited his primary-care physician with a 3-day history of fever and severe malaise. He had no history of diabetes mellitus or active disease. He was admitted and treated with intravenous meropenem (MEPM) at $1 \mathrm{~g} /$ day and oral levofloxacin at $500 \mathrm{mg} /$ day by his primary-care physician on day 1 . The next day, a Gram-negative bacillus was detected from two sets of blood culture bottles. The patient was then transferred to our hospital for further examination and treatment. $\mathrm{He}$ was conscious. Body temperature was $37.7^{\circ} \mathrm{C}$, heart rate was 80 beats per minute, respiratory rate was 14 breaths per minute, and blood pressure was $113 / 70 \mathrm{mmHg}$. There were no significant findings on physical examination, chest X-ray, plain computed tomography of the head, whole-body contrast-enhanced computed tomography, transthoracic echocardiography, or colonoscopy. Blood testing revealed a white blood cell count of 8080 cells/ $\mu \mathrm{l}$, a C-reactive protein (CRP) level of $18.01 \mathrm{mg} / \mathrm{dl}$, and a procalcitonin level of $1.02 \mathrm{ng} / \mathrm{ml}$. Blood and urine cultures were negative. Intravenous MEPM ( $3 \mathrm{~g} /$ day) was administered at our hospital owing to a lack of improvement on the previous treatment (day 2). He was afebrile on day 3. CRP level decreased to $4.05 \mathrm{mg} / \mathrm{dl}$ on day 5 . A blood culture taken by the previous physician reportedly revealed C. sakazakii. Antibiotic therapy was changed to ceftriaxone at $2 \mathrm{~g} /$ day based on the results of antimicrobial susceptibility testing on day 6 (Table 1 ). This treatment was stopped on day 10 after confirming normalization of CRP levels and negative results for blood
Table 1 Antibacterial susceptibility test results of the strain isolated in the present case

\begin{tabular}{lll}
\hline Antimicrobial agent & MIC $(\boldsymbol{\mu g} / \mathbf{m l})$ & $\begin{array}{l}\text { Interpretation } \\
\text { according to CLSI } \\
\mathbf{2 0 1 2} \text { criteria }\end{array}$ \\
\hline Ampicillin & $>16$ & $\mathrm{R}$ \\
Piperacillin & $\leq 16$ & $\mathrm{~S}$ \\
Cefazolin & $>16$ & $\mathrm{R}$ \\
Cefotiam & $>16$ & $\mathrm{R}$ \\
Cefotaxime & $\leq 1$ & $\mathrm{~S}$ \\
Cefepime & $\leq 8$ & $\mathrm{~S}$ \\
Imipenem/cilastatin & $\leq 1$ & $\mathrm{~S}$ \\
Gentamicin & $\leq 4$ & $\mathrm{~S}$ \\
Minocycline & $\leq 4$ & $\mathrm{~S}$ \\
Levofloxacin & $\leq 2$ & $\mathrm{~S}$ \\
\hline
\end{tabular}

MIC, minimum inhibitory concentration; CLSI, Clinical and Laboratory Standards Institute; $\mathrm{R}$, resistant; $\mathrm{S}$, susceptible.

culture. After discontinuation of antibiotic therapy and discharge from our hospital, the patient showed good progress without recurrence of fever. Biochemical analyses using the MicroScan WalkAway 96 system (Beckman Coulter, Brea, CA, USA) identified the causative organism as C. sakazakii (Table 2). However, the colonies on the blood agar medium unexpectedly showed grayish coloration, differing from the yellowish coloration of typical Cronobacter colonies (Fig. 1). MALDI-TOF MS using Microflex LT with the Biotyper v3.1 database (Bruker Daltonics, Bremen, Germany) was therefore conducted. MALDI-TOF MS identified the bacterium as E. asburiae on three independent analyses ( $\log$ score values of 2.19 , 2.08 , and 2.20, matching with $E$. asburiae type strain DSM 17506). Finally, multilocus sequence analysis using five housekeeping genes (fusA, gyrB, leuS, rpoB, and hsp60) [4] confirmed our isolate as E. asburiae (TWCC 57976). Nucleotide sequence data reported are available under the DNA Data Bank of Japan (DDBJ) accession numbers LC427844 to LC427849.

\section{Discussion and conclusions}

In this case, biochemical analyses misidentified E. asburiae as C. sakazakii. As C. sakazakii can contaminate powdered infant formula and may cause fatal infections in newborns, biochemical screening for Cronobacter contamination is recommended [5]. Although accurate identification of C. sakazakii is extremely important to prevent potentially fatal infections of newborns, a previous study suggested that biochemical test panels are unreliable for identifying Cronobacter species [6]. To avoid misidentification, methods other than biochemical analyses need to be considered. 
Table 2 Biochemical phenotypes of E. asburiae and C. sakazakii in reference to the MicroScan WalkAway 96 system and results for the strain isolated in the present case

\begin{tabular}{llll}
\hline & E. asburiae & C. sakazakii & Present case \\
\hline Glucose & 99 & 99 & + \\
Sucrose & 99 & 99 & + \\
Sorbitol & 99 & 5 & - \\
Raffinose & 50 & 90 & + \\
Rhamnose & 5 & 99 & + \\
Arabinose & 95 & 99 & + \\
Inositol & 10 & 75 & + \\
Adonitol & 1 & 1 & - \\
Melibiose & 5 & 90 & + \\
Urease & 1 & 1 & - \\
Hydrogen sulfide & 1 & 1 & - \\
Indole & 1 & 1 & - \\
Lysine decarboxylase & 1 & 1 & - \\
Arginine decarboxylase & 25 & 75 & - \\
Ornithine decarboxylase & 95 & 95 & + \\
Tryptophan deaminase & 1 & 1 & - \\
Esculin hydrolysis & 90 & 95 & + \\
Voges-Proskauer & 1 & 95 & + \\
Citrate & 25 & 99 & + \\
Malonate & 1 & 10 & + \\
B-Galactosidase & 99 & 99 & + \\
\hline
\end{tabular}

Each number represents the probability of biochemical reaction.

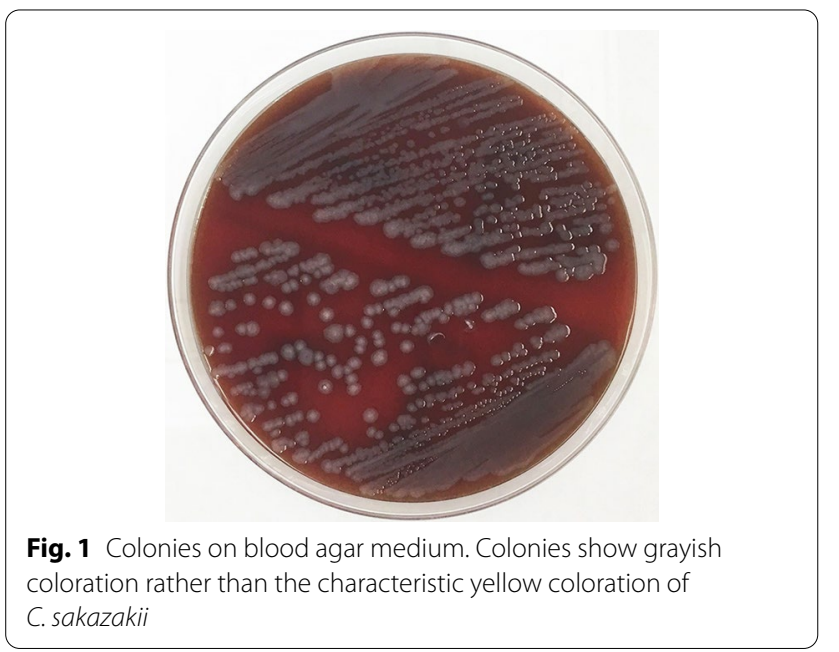

The biochemical misidentification in this case may have been caused by biochemical heterogeneity of bacteria. In the MicroScan WalkAway system, negativity for sorbitol fermentation and positivity for melibiose, rhamnose, and inositol fermentation and the
Voges-Proskauer reaction matched the typical biochemical phenotype of $C$. sakazakii, but not that of E. asburiae. E. asburiae belongs to the Enterobacter cloacae complex. Six species of bacteria belong to this complex, which share similar biochemical phenotypes [7]. C. sakazakii was previously categorized as Enterobacter sakazakii, but was later recategorized into genus Cronobacter [3]. A previous report described C. sakazakii biochemically misidentified as E. hormaechei, belonging to the E. cloacae complex [8]. They suggested that misidentification of $E$. hormaechei as C. sakazakii may cause unnecessary financial losses for manufacturing companies. The activities of enzymes that determine the biochemical phenotype are heterogeneous and can cause misidentification of Cronobacter [9]. Biochemical misidentification among related strains has been reported in other bacteria, such as Pseudomonas aeruginosa [10] and enterohemorrhagic Escherichia coli [11]. Such misidentifications can lead to the prescription of inappropriate antibiotics and serious infection. Additional tests in consideration of the possibility of misidentification by biochemical analyses should be considered.

MALDI-TOF MS is a mass spectrometry technique that involves ionizing a sample using laser light and patterning constituent molecules of the target protein. Bacteria can be identified by comparing the constituent molecular pattern (mass spectrum) of the obtained material with a database [1]. This method is simple and quick compared with DNA-sequence-based methods. The effects of reducing hospitalization days and mortality rates through the proper use of antibiotics based on MALDI-TOF MS results have also been reported [12]. Further, MALDI-TOF MS allows quick identification of bacteria that show poor cultivation rates or long cultivation periods, improving the bacterial identification rate [13].

In our case, E. asburiae was initially biochemically misidentified as C. sakazakii before correct identification by MALDI-TOF MS. Although the significance of $E$. asburiae bacteremia has not been elucidated, its prevalence may be underestimated due to the misidentification of E. asburiae bacteremia. MALDI-TOF MS has the possibility of reducing misidentification and improving reporting rates of $E$. asburiae. This technique may also help elucidate the natural history of the bacteria. When biochemical misidentification of bacteria is suspected, MALDI-TOF MS should be considered for rapid and accurate identification.

\section{Abbreviations}

MALDI-TOF MS: Matrix-assisted laser desorption/ionization time-of-flight mass spectrometry; MEPM: Meropenem; CRP: C-reactive protein. 


\section{Acknowledgements}

We wish to thank Yuko Arai, Ryo Mizushima, Keisuke Kamada, Yasutomo Itakura, Shigekazu Iguchi, and Yutaka Uzawa for their excellent technical assistance.

\section{Authors' contributions}

$\mathrm{NH}$ collected and analyzed the data and drafted the manuscript. SS and TT collected the data and participated in developing the concept of the manuscript. AY, KK, and AN analyzed the data. EM participated in developing the concept of the manuscript and revised the article for important intellectual content. All authors read and approved the final manuscript.

\section{Funding}

This report received no specific grant from any funding agency in the public, commercial, or not-for-profit sector.

\section{Availability of data and materials}

Not applicable.

\section{Declarations}

\section{Ethics approval and consent to participate}

Ethics approval was not required by the ethics committees at Almeida Memorial Hospital and Oita University.

\section{Consent for publication}

Written informed consent was obtained from the patient for publication of this case report and the accompanying images. A copy of the written consent is available for review by the Editor-in-Chief of this journal.

\section{Competing interests}

The authors declare that they have no competing interests.

\section{Author details}

'Department of General Medicine, Almeida Memorial Hospital, 1509-2 Miyazaki, Oita, Oita 870-1195, Japan. ${ }^{2}$ Department of General Medicine, Faculty of Medicine, Oita University, 1-1 Idaigaoka Hasama-machi, Yufu, Oita 879-5593, Japan. ${ }^{3}$ Department of Infectious Diseases, Tokyo Women's Medical University, 8-1 Kawada-cho, Shinjuku-ku, Tokyo 162-8666, Japan. ${ }^{4}$ Department of Microbiology, Faculty of Medicine, Oita University, 1-1 Idaigaoka, Hasama-machi, Yufu, Oita 879-5593, Japan.

Received: 29 July 2021 Accepted: 22 December 2021

Published online: 19 January 2022

\section{References}

1. P Rahi O Prakash YS Shouche 2016 Matrix-assisted laser desorption/ionization time-of-flight mass-spectrometry (MALDI-TOF MS) based microbial identifications: challenges and scopes for microbial ecologists Front Microbiol 71359

2. R Stephan D Ziegler V Pfluger G Vogel A Lehner 2010 Rapid genus- and species-specific identification of Cronobacter spp. by matrix-assisted laser desorption ionization-time of flight mass spectrometry J Clin Microbiol 4828462851

3. JJ Farmer 3rd 2015 My 40-year history with Cronobacter/Enterobacter sakazakii-lessons learned, myths debunked, and recommendations Front Pediatr 384

4. A Paauw MP Caspers FH Schuren MA Leverstein-van Hall A Deletoile RC Montijn 2008 Genomic diversity within the Enterobacter cloacae complex PLOS ONE 3 e3018

5. Y Chen KY Song EW Brown KA Lampel 2010 Development of an improved protocol for the isolation and detection of Enterobacter sakazakii (Cronobacter) from powdered infant formula J Food Prot 731016 1022

6. EE Jackson SJ Forsythe 2016 Comparative study of Cronobacter identification according to phenotyping methods BMC Microbiol 16146

7. ML Mezzatesta F Gona S Stefani 2012 Enterobacter cloacae complex: clinical impact and emerging antibiotic resistance Future Microbiol 7887902
8. SM Townsend E Hurrell J Caubilla-Barron C Loc-Carrillo SJ Forsythe 2008 Characterization of an extended-spectrum beta-lactamase Enterobacter hormaechei nosocomial outbreak, and other Enterobacter hormaechei misidentified as Cronobacter (Enterobacter) sakazakii Microbiology. 154 36593667

9. P Druggan C Iversen 2009 Culture media for the isolation of Cronobacter spp Int J Food Microbiol 136169178

10. N Wellinghausen J Kothe B Wirths A Sigge S Poppert 2005 Superiority of molecular techniques for identification of Gram-negative, oxidase-positive rods, including morphologically nontypical Pseudomonas aeruginosa, from patients with cystic fibrosis J Clin Microbiol 4340704075

11. LK Crawford-Miksza S Himathongkham ML Dodd AS Badoiu OM Badoiu LS Guthertz 2009 Misidentification of a variant biotype of Escherichia coli O157:H7 as Escherichia fergusonii by Vitek 2 Compact J Clin Microbiol 47 872873

12. AM Huang D Newton A Kunapuli TN Gandhi LL Washer J Isip 2013 Impact of rapid organism identification via matrix-assisted laser desorption/ionization time-of-flight combined with antimicrobial stewardship team intervention in adult patients with bacteremia and candidemia Clin Infect Dis 5712371245

13. S Biswas JM Rolain 2013 Use of MALDI-TOF mass spectrometry for identification of bacteria that are difficult to culture J Microbiol Methods 9214 24

\section{Publisher's Note}

Springer Nature remains neutral with regard to jurisdictional claims in published maps and institutional affiliations.
Ready to submit your research? Choose BMC and benefit from:

- fast, convenient online submission

- thorough peer review by experienced researchers in your field

- rapid publication on acceptance

- support for research data, including large and complex data types

- gold Open Access which fosters wider collaboration and increased citations

- maximum visibility for your research: over 100M website views per year

At BMC, research is always in progress.

Learn more biomedcentral.com/submissions 